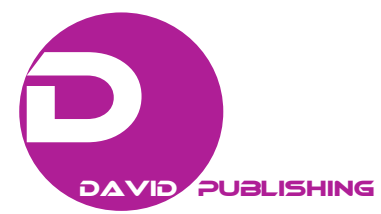

\title{
Understanding Zika Outbreak through Security Lense: A Hasty Global Health Panic
}

\author{
Ahmad Alfajri-Riana Mardila \\ Department of International Relation, Syarif Hidayatullah State Islamic University Jakarta, Tangerang Selatan, DKI Jakarta 15412, \\ Indonesia
}

\begin{abstract}
In 2015, the Zika outbreak has caused a global panic. It spreads rapidly from the Latin land (Brazil), North America (United States of America), to Asia (such as Indonesia, Malaysia). USA, as a superpower country, made it seem critical as he requested emergency fund $\$ 1.8$ billion from his national state's budgetary to prevent and to treat this disease. Brazil undertook securitization act, a strong word and action, called "war to mosquito" as a treatment and prevention act. In addition, World Health Organization (WHO) required \$56 million to implement the Strategic Response Framework and Joint Operations Plan due to this issue. These undertaken actions therefore wrapped the Zika outbreak likely as a global health conundrum. Is it really a global health issue? Does it need securitization? These are the questions that this article is going to cover. This paper aims to search in what frame Zika outbreak should be categorized appropriately. This article uses qualitative method with library research in answering the research question. It is conducted through "International Relation" perspective by specifically using Barry Buzan's securitization concept. We will first determine whether Zika is a threat to national or international security. Second, we will discuss whether or not it is necessary to securitize Zika. It is also followed by analysis on what consequences if securitization is held. Finally, we argue that based on Buzan's securitization concept, Zika is not a threat to national and international security. Therefore, securitization is unnecessary as it does not pose an existential threat to international order, state, and society in a large scale. In addition, securitization itself entails a demanding consequences that has not been needed. In conclusion, we argue that Zika outbreak is a hasty global health panic that instead should be framed as a public health issue.
\end{abstract}

Key words: Zika threat, national security, international security, security, securitization.

\section{Introduction}

Zika Virus (ZIKV) is not a new "discovery". It has been discovered in 1947 in the Uganda's forest affecting monkeys, small rodents, and less frequently human beings [1]. However, its first documentation was in 2007 reported from Yap State, Micronesia, followed in 2013 in French Polynesia. In 2015, it was sporadic in Brazil which at that time was about to host Olympic in 2016 and reached the southern part of US [2]. Fifty-eight countries are reported having ZIKV infection [2].

World Health Organization (WHO) and its partners seem to put a quite responsive and supportive action towards this issue especially after its outbreak in Brazil and USA in 2015. WHO declared ZIKV constitute to

Corresponding author: Riana Mardila, MIR, research fields: international relations, human security, global health.
PHEIC (Public Health Emergencies of International Concern) in February 2016. PHEIC itself is referred by WHO as an extraordinary event in which it establishes a public health risk to other states through the international spread of disease and necessitates a coordinated international response [2]. Over years, WHO has declared PHEIC for four times. First, April 2009 for H1N1 (or Swine Flu) pandemic, followed by polio in May 2014, the outbreak of Ebola in Western Africa in August 2014, and February 2016, for mosquito-borne ZIKV in relation to microcephaly, birth defects, and spreading rapidly. PHEIC declaration on ZIKV does not mean ZIKV is being securitized. However, it implies that the widespread of ZIKV is a serious issue, unusual or unexpected which calls and requires immediate action both nationally (especially the affected countries) and globally. 
"WHO also requires $\$ 56$ million to implement the Strategic Response Framework and Joint Operations Plan, which \$25 million would fund the WHO/AMRO (American Regional Office)/PAHO (Pan American Health Organization) response and \$31 million would fund the work of key partners" [2]. In the USA, President Obama has requested $\$ 1.8$ billion in emergency funding for prevention and treatment [3]. In Brazil itself, the securitization of ZIKV is conducted by "war on mosquito" which turned the Aedes aegypti as the number one public health enemy [4].

Given the brief background, this essay sees that Zika currently has been framed as a frightening case considering the way news report it and the announcement that Zika constitutes to PHEIC. It is indeed a responsive response which is always good in preventing the outbreak. However, the way it is framed is seemed appropriate.

This essay examines how Zika should be framed appropriately. It starts with a question whether or not Zika is a threat to national and international security and whether or not the securitization is needed. As this essay argues that Zika is not a threat to national and international security, in the end this essay proposes that Zika should be treated as a public health issue instead of securitizing it. It seems more rationale to treat Zika by providing a more comprehensive public infrastructure in the national sphere first before elevating it into global sphere concern.

\section{Method}

This essay uses the library research as a method to investigate the questions. It uses the concept of securitization by Bary Buzan. He explains that "threat are socially constructed thus any issue can be securitized depending on the circumstance" [5]. However, this essay also considers the "threat" is defined by the human security concept. Human security concept defines threat as things causing human insecurity. To be clear, human security itself covers seven points: economic, food, health, environmental, personal, communal, and political security [6]. Therefore human insecurity means insecurity to those seven aspects. Building on that, this essay defines something to be a threat to national and international security if it poses an existential threat to states, international order, and to large number of people. It is a broad definition as this essay tries to accommodate or to bridge the potential threat that is defined by Buzan and the human security concept.

\section{Results \& Discussion}

\subsection{Zika Is Not a Threat to National and International Security}

Referring to the previous definition, we argue that Zika is not a threat to national and international security because first, it does not pose a threat to or destabilize the national and international order. The reason is based on the comparison between Zika and Ebola. Zika is unlike Ebola that has been declared as "a threat to international peace and security" [7]. There were more than 8,000 cases and caused 11,310 people died [7]. It was a hopeless condition in which states could not handle it not only regarding the financial condition but also the capacity to provide the medical infrastructure (such as beds, hospital and medicine) and service (such as doctors and nurse). Margaret Chan, Director-General of the WHO, claimed Ebola as the infectious disease contributes to potential state in which it has lost control over its borders and territory, has lost legitimacy and authority in decision-making and is unable to provide public services [7]. At that time, the World Bank estimated that affected countries in Africa will lose $\$ 32.6$ billion by the end of 2015 if the Ebola goes unchecked [7].

Based on that comparison, we do not see Zika as a disease that has paralysed the state or international order because what it cost. It is indeed emotional to see the poor babies with microcephaly and long life disability. We agree if this is considered as a threat through human security lenses that has been discussed earlier. It is indeed a case of health insecurity. However, 
in a broader context, it does not pose a massive "destruction" to the state and international order that require a securitization.

The second reason is that Zika does not pose an existential threat to a large number of people as it can still be prevented. It can be (simply) prevented because ZIKV does not cause death. It is only a mild symptom that will last two to twelve days in normal people. Though it causes microcephaly and long life disability to the newborn babies, it still does not cause death like other infectious diseases. For instance, Ebola has caused 11,310 people died [8]. Polio, even though now it is decreasing, but it causes paralysis, and $5 \%$ to $10 \%$ of paralysed cases died when their breathing muscles become immobilized [9]. Swine flu from 60.8 million cases in 2009 to $2010,12,469$ people died [10]. AIDS has caused 1.2 million people die and 36.9 million people living with HIV/AIDS worldwide [11]. Meanwhile, there has not been any report reporting Zika causes death. Regarding Zika followed by microcephaly, Brazil reported that there were 4,783 suspected cases of microcephaly which 1,132 (24\%) of it has been classified. From such classification, 404 (36\%) out of 1,132 cases had confirmed microcephaly and central nervous system malformation and yet only 17 (4\%) of 404 were positive for having ZIKV infection [12]. In addition, Zika has a clear process of transmission which can be mitigated as a prevention effort. ZIKV itself is transmitted to human through mosquitos' (Aedes aegypty and Aedes albopictus) bite. However, human to human vector transmission can occur especially during the outbreak. It can be transmitted through pregnancy (mother to her baby), blood transfusion, and sexual contact. It brings several symptoms that resemble dengue fever: fever, joint pain, rash, and conjunctiva (red eyes).

Though at the moment there has not been any vaccine or special medical treatment for ZIKV infection, prevention can be done by actually avoiding those patterns. The mild symptoms can be treated with taking fluids, rest, and oral analgesics and antipyretics for fever and pain relief. People are suggested to use mosquito repellent, close the medium or places that can potentially reproduce the mosquito, do not travel to the infected countries, and postpone of having sexual contact and pregnancy post-travelling to the infected countries. It is not like swine flu that can be contagious because of airborne cause like inhaling or touching things containing the virus or respiratory droplets (coughing or sneezing) [10]. Zika is also not like polio in which $72 \%$ of vulnerable persons infected with polio which does not show any particular symptoms. However, infected persons without symptoms can still spread the virus and cause others to develop polio, and the susceptible persons themselves will be weakened; several cases cause meningitis, paralysis, and worst of all is death [9]. Zika is also unlike Ebola that can be widespread easily as people who have close contact with Ebola patients (through blood or body fluids), or direct contact with contaminated objects (like clothes, bedding, needles, etc.), or infected wildlife [13].

\subsection{Zika Should Not Be Securitized, It Should Be} Framed as a Public Health Issue

As we argue that Zika is not a threat to national and international security, we continue to argue that securitization would be unnecessary. According to Ingram [14], securitization entails obligation which are anticipation of threats which do not yet exist or have not been fully formed; preparedness that will enable responses to a broad spectrum of emergencies; understanding the issue regarding emergent risks and it takes the form of pre-emption. Therefore, securitization will be unnecessary because first, it will cost an ineffective funding. It is quite a huge spending if nationally or globally Zika asks for anticipation (before Zika itself presence in one state) which required emergency risk-preparedness and pre-emptive actions in all aspects; border, trade, economy, military, etc. It will require a special enormous fund that will be spent on the research, providing the medical treatment (vaccine or drugs), technology to do so, military on the 
border (personals and material things such as military transport and weapon, foods for the personals army, military technology, etc), security and medical technology in the airport, administrative budget for massive socialization, etc. Meanwhile, as Zika can still be prevented, then such allocation is ineffective and supposedly can be allocated to the more urgent ones.

Second, it will shift the national or global priority. It is not only costly in spending but "costly" in how some policies will domestically or globally be shifted. For example, as state focus on Zika, all priority is focused on Zika. Meanwhile, other disease or other social aspects (education, poverty, infrastructure, etc.) may need similar or more attention and may be more urgent. It will be hard for developing countries, for instance, some countries in Africa, may not yet suffer Zika but has to prepare and pre-empt for Zika as if it is treated as a threat. Meanwhile, they still struggle to fight the Ebola, which is more dangerous. It will also affect the trade-economy scheme in which states suffered Zika may get less advantaged as such states are claimed to be vulnerable and source of the disease. It may also affect the economy in particular aspect such as tourism as the tourist will be selective to go to infected countries which will influence the local economy or even worst, the fall of currency peg of those infected countries.

Based on these consequences, we think Zika should be framed as a public health issue. It is true that the fact that Zika belongs to PHEIC means that it is already a public health issue. However, we think that PHEIC is also another conundrum in which it wraps Zika more in a global-public health issue rather than public health issue per se. Referring to National Security for the United States (2002), Fidler [15] quoted that “...public health and health care systems has become a matter of national and homeland security concern." Therefore, we argue that Zika should be framed as a public health issue because it requires more the capacity of the state (that suffer Zika) to provide a qualified and accessible health related public infrastructure rather than the global society as a whole. For example, the availability of clean water and sanitation, accessible health care, proper hospital, appropriate housing, etc at the end related to the efforts of the poverty eradication.

\section{Conclusions}

We agree that Zika is a serious issue as PHEIC has declared so. Nonetheless, we disagree if Zika should be framed as a threat to national and international security and wrapped it as a global health or global-public health issue like PHEIC does. It is unnecessary as it does not destabilize the state and international order and it does not pose an existential threat to a large number of people as it can still be prevented. In addition, securitization will be exaggerated as it will bring unnecessary consequences such as ineffective spending and the shift of national priority. Therefore, we argue that conceptualizing Zika as a public health issue is more appropriate as it focuses on providing more qualified and accessible health system and infrastructure which belongs to every state responsibility.

\section{References}

[1] Granato, C., Lázari, C., and Serafini, P. C. 2016. "New Threat on the Horizon: The Zika Virus." International Journal of Gynecology and Obstetrics 133 (2) 137-8.

[2] World Health Organization (WHO). 2016. Zika Outbreak: WHO's Global Emergency Response Plan. Retrieved from http://www.who.int/emergencies/zika-virus/response/en/.

[3] Belluck, P., and McNeil Jr, D. G. 2016. "Extensive Brain Defects Seen in Babies of Mothers With Zika." Retrieved from

https://www.nytimes.com/2016/12/13/health/zika-virus-b aby-brain-defects.html.

[4] Ventura, D. F. L. 2016. "From Ebola to Zika: International Emergencies and the Securitization of Global Health." Cad. Saúde Pública (Rio de Janeiro) 32 (4): e00033316.

[5] Buzan, B., Wæver, O., and Wilde, J. D. 1998. Security: A New Framework for Analysis. Boulder: Lynne Rienner.

[6] United Nations Development Program (UNDP). 1994. Human Development Report 1994. United Nations Development Program, New York.

[7] Sagan, C. 2015. "Ebola, A Threat or Security?" The Stanford Journal of Public Health. Retrieved from https://web.stanford.edu/group/sjph/cgi-bin/sjphsite/ebola 
-securitized/.

[8] Centers for Disease Control and Prevention (CDC). 2015. Ebola (Ebola Virus Disease): 2014 Ebola Outbreak in West Africa-Case Counts. Retrieved from http://www.cdc.gov/vhf/ebola/outbreaks/2014-west-africa /case-counts.html.

[9] Centers for Disease Control and Prevention (CDC). 2014. Vaccines \& Immunization: Polio Disease. Retrieved from http://www.cdc.gov/vaccines/vpd-vac/polio/dis-faqs.htm.

[10] Centers for Disease Control and Prevention (CDC). 2014. H1N1. Retrieved from http://www.cdc.gov/h1n1flu/estimates_2009_h1n1.htm.

[11] World Health Organization (WHO). 2016. HIV/AIDS.
Retrieved from http://www.who.int/gho/hiv/en/.

[12] CHEN, H. L., and TANG, R. B. 2016. "Why Zika Virus Infection Has Become a Public Health Concern?" Journal of the Chinese Medical Association 79 (4): 174-8.

[13] Centers for Disease Control and Prevention (CDC). 2015. Ebola (Ebola Virus Disease): Transmission. Retrieved from http://www.cdc.gov/vhf/ebola/transmission/.

[14] Ingram, A. 2010. "Biosecurity and the International Response to HIV/AIDS: Governmentality, Globalization, and Security." Area 42 (3): 293-301.

[15] Fidler, D. P. 2005. "Health as Foreign Policy: Between Principle and Power." The Whitehead Journal of Diplomacy and International Relations 6: 179-94. 